\title{
Phenotypic Screening for Brown Planthopper [Nilaparvata lugens (Stål)] Resistance in Rice (Oryza sativa L.)
}

\author{
S.P. Timmanagouda ${ }^{1^{*}}$ and M. Maheswaran ${ }^{2}$ \\ ${ }^{1}$ Department of Genetics and Plant Breeding, University of Agricultural Sciences, \\ Bengaluru, Karnataka, India \\ ${ }^{2}$ Director of Research, Tamil Nadu Agricultural University, Coimbatore-641003, \\ Tamil Nadu, India \\ *Corresponding author
}

\section{A B S T R A C T}

\begin{tabular}{|l|}
\hline Ke y w or d s \\
Rice, Brown \\
planthopper, \\
Modified seed-box \\
Screening test, Days \\
to wilt and \\
resistance.
\end{tabular}

Experiments were conducted to screen a set of rice accessions to assess their level of resistance to BPH infestation. Out of 25 rice entries subjected to Modified Seedbox Screening Test (MSST), 21 entries viz. Rasi, Chethunali, Ganthasala, Blue bonnet, Branava, Slivahaiva, Blue bell, Rajshree, WGL 14, White ponni, Aathira, Brimfer, Uttrirajappan, Basmati 370, Swarana, Vethi vedangan, Karanellu, Columbia 2, WAGWAG, White sannam and TN1 were found to be highly susceptible with the damage score ranging from 7.00 to 9.00. Three entries viz. Kakarathan, BG367-2 and Kavuni were found to be moderately resistant with damage score of 5.77, 5.81 and 6.73 respectively. Bharathi was found to be resistant with the damage score of 1.90. Four rice entries viz. Columbia 2, WAGWAG, White sannam and TN1 remained with damage score of 9.0 indicating their susceptibility to BPH. The accessions were subjected to screening based on days to wilt. Bromfer, Blue bell, BG367-2, Karkarathan, Kavuni and Uttrirajappan were showing delayed wilting compared to Bharathi.

\section{Introduction}

Rice is one of the agronomically and nutritionally important cereal crops and it is the principal staple food in developing countries. China and India together account for more than half of world's rice area and, along with Indonesia consume more than three- fourth of the global rice production (Hossain, 1997; MacLean, 2002). Given that the world's population is expected to reach nine billion by 2045 (US Census Bureau, 2009), the importance of reducing losses from pests gains greater focus. Only 18-20 species out of nearly 800 insect pest species recorded on rice, are major pests in tropical Asia. There is a small stone image of Buddha in Fukuoka, a northern city of Kyushu, Japan enshrined for mourning a million farmers perished with historical famine caused by an outbreak of the brown planthopper [Nilaparvata lugens (Stål)] over the western part of Japan in 1732 (Suenaga and Nakatsuka, 1958). BPH is a monophagous pest on rice and is known for its sudden outbreak. Since the remote past, such sporadic BPH outbreaks were catastrophic in the traditional rice farming in Japan and South East Asian countries. These 
outbreaks were mainly due to the indiscriminate and massive use of insecticides in rice farming.

Deployment of BPH-resistant IR varieties was aimed to solve the BPH menace. However, the sequential release of BPH-resistant IR varieties with new resistance genes was easily defeated with successive emergence of adaptive BPH biotypes (Sogawa, 1982; Gallagher et al., 1994). Persistent BPH outbreaks in the tropical Asia once declined and were put under control by the Integrated Pest Management (IPM), extension projects by Food and Agricultural Organisation (FAO) and International Rice Research Institute (IRRI) (Pontius et al., 2002).

However, $\mathrm{BPH}$ is once again threatening the rice farming in Asia at far more serious scales than previous outbreaks under intensified cropping patterns due to the use of prophylactic insecticides, extension of hybrid rice, and changes in socio-economic and political situations surrounding the rice agriculture (Bottrell and Schoenly, 2012). To overcome the problem due to $\mathrm{BPH}$, exploitation of host plant resistance is being adopted as one of the strategies by IRRI in 1970s. In the present study, an attempt was made to assess the varying levels of resistance to $\mathrm{BPH}$ in land races of rice.

\section{Materials and Methods}

\section{Insect source for screening}

The BPH was mass reared on the susceptible Taichung Native 1 (TN1) following the method of Heinrichs et al., (1985). Initial $\mathrm{BPH}$ population was collected from the rice fields at the Paddy Breeding Station (PBS), Coimbatore. The adults were confined on 35 days old potted plants of TN1 placed in oviposition cages $(45 \times 45 \times 60 \mathrm{~cm})$ having wooden frames, glass top, door and wire mesh sidewalls. The ovipositing insects were removed three days later and plants with eggs were taken out of cages, placed in separate cages for the nymphs to emerge. The emerged nymphs were then transferred to 15 days old TN1 seedlings raised in the germination trays, which in turn were placed in galvanized iron trays of $62 \times 47 \times 15 \mathrm{~cm}$ size containing $5 \mathrm{~cm}$ depth of water to increase humidity and to avoid watering daily. The seedling trays were changed as and when necessary. Using this technique, a continuous culture of the $\mathrm{BPH}$ was maintained throughout the period of study.

\section{Plant materials}

A set of 25 rice accessions (Table 1) received from Regional Agricultural Research Station, Pattambi and Paddy Breeding Station, TNAU were screened for assessing their levels of resistance to $\mathrm{BPH}$ at seedling stage.

\section{Methods}

Phenotypic screening for assessing the levels of resistance to $\mathrm{BPH}$ across the 25 rice accessions was carried out involving two screening methods viz., Modified Seed-box Screening Test (MSST) and Days to wilt (DW) developed by Velusamy et al., (1986) and Soundararajan et al., (2004) respectively.

\section{Seedling stage screening by modified seed-} box screening test (MSST)

The MSST was used to assess the levels of resistance to $\mathrm{BPH}$ across the rice accessions at the seedling stage. Wooden box of standard size $50 \times 40 \times 10.5 \mathrm{~cm}$ was filled with fine wet soil and levelled properly. Pre-germinated seeds of each entry (at least 25 seeds per entry) were sown $3 \mathrm{~cm}$ apart in the wooden box in such a way that it could accommodate 12 lines per seed-box including the resistant check PTB33 and susceptible check TN1. On 
the third day of seeding, the wooden seedboxes were transferred to galvanized iron trays $(62 \times 47 \times 15 \mathrm{~cm})$ containing $5 \mathrm{~cm}$ depth of water. Twelve days after sowing (DAS), the seedlings were infested with first to second instar nymphs at the rate of three to five nymphs per seedling. After infestation, the wooden seed-boxes with seedlings were covered with wire mesh wooden cages. Three replications for each genotype along with a control were maintained.

The test plants were observed daily for $\mathrm{BPH}$ damage. After one generation of insect establishment (approximately 20 days after infestation) hopper burn symptoms caused due to BPH damage were observed on test lines.

Damage rating of the test lines was done on a row basis, when 90 per cent of the plants either in the susceptible check row or susceptible genotype in the seed-box were killed. The test lines were scored on a 1-9 scale using the Standard Evaluation System (SES) for Rice (IRRI, 1996). The plants with score 0-3 were considered as resistant, 3.1 to 6.9 as moderately resistant and $7-9$ as susceptible (Table 4).

\section{Tillering stage screening based on days to wilt method (DW)}

Days to wilt was used as a measure of tolerance where the damage by $\mathrm{BPH}$ population on each accession was decided by counting the number of days required to kill the plants after insect infestation. Pregerminated seeds were sown on $15 \mathrm{~cm}$ diameter clay pots and emerging seedlings were caged with cylindrical mylar sheet cage $(14 \times 110 \mathrm{~cm})$. Forty five days after sowing, 50 numbers of first to second instar nymphs were released on the plants and allowed to feed. The day on which the plant wilted completely was recorded. The experiment was conducted in a Complete Randomized Block Design (CRBD) with eight replications for each genotype along with three control plants.

\section{Results and Discussion}

In the present study, attempts were made to assess the levels of resistance of 25 landraces of rice using two parameters viz., damage score based on MSST (Velusamy et al., 1986) and newly established days to wilt (Soundarajan et al., 2004). Out of 25 rice entries subjected to MSST, 21 entries viz. Rasi, Chethunali, Ganthasala Blue bonnet, Branava, Slivahaiva, Blue bell, Rajshree, WGL 14, White ponni, Aathira, Brimfer Uttrirajappan, Basmati 370, Swarana, Vethi vedangan, Karanellu, Columbia 2, WAGWAG, White sannam and TN1 were found to be highly susceptible with the damage score ranging from 7.00 to 9.00. Three entries viz. Kakarathan, BG367-2 and Kavuni were found to be moderately resistant. Of the 25 entries, Bharathi was found to be with minimum damage score of 1.90 indicating the highest level of resistance to $\mathrm{BPH}$, whereas Columbia 2, WAGWAG, White sannam and TN1 were found to be with damage score of 9.0 indicating their high susceptibility (Table 1). Though MSST differentiates resistant and susceptible genotypes it cannot clearly expose the causes behind resistance or susceptibility.

The accessions screened based on MSST were subjected to another screening method developed by Soundararajan et al., (2004) wherein known number of insects were allowed to infest individual rice plants 45 days after sowing and the number days taken for the complete wilting was observed. The data generated from this method based on days to wilt is clearly quantitative and differentiates the accessions without much overlapping. 
Table.1 Mean scores for the BPH resistance across rice entries screened by MSST method and days to wilt

\begin{tabular}{|l|c|c|}
\hline Accession & Damage Score & Days to wilt \\
\hline Aathira & 8.43 & 7.25 \\
\hline Basmati 370 & 8.67 & 8.13 \\
\hline BG367-2 & 5.81 & 21.75 \\
\hline Blue bell & 8.13 & 21.88 \\
\hline Blue bonnet & 8.01 & 9.38 \\
\hline Branava & 8.03 & 9.50 \\
\hline Brimfer & 8.57 & 21.88 \\
\hline Chethunali & 7.51 & 10.00 \\
\hline Columbia 2 & 9.00 & 9.63 \\
\hline Ganthasala & 7.73 & 9.63 \\
\hline WAGWAG & 9.00 & 9.00 \\
\hline Kakarathan & 5.77 & 19.13 \\
\hline Karanellu & 8.88 & 8.38 \\
\hline Kavuni & 6.73 & 16.25 \\
\hline Rajshree & 8.21 & 8.13 \\
\hline Rasi & 7.26 & 9.50 \\
\hline Slivahaiva & 8.10 & 13.13 \\
\hline Swarana & 8.73 & 9.25 \\
\hline Uttrirajappan & 8.65 & 15.88 \\
\hline Vethi vedangan & 8.77 & 11.25 \\
\hline WGL 14 & 8.29 & 11.13 \\
\hline White ponni & 8.40 & 10.75 \\
\hline White sannam & 9.00 & 10.50 \\
\hline Bharathi & 1.90 & 14.50 \\
\hline TN1 & 9.00 & 10.00 \\
\hline
\end{tabular}

Table.2 ANOVA for damage score by MSST method

\begin{tabular}{|l|c|c|c|c|c|}
\hline Source & df & SS & MS & F & PROB \\
\hline Replication & 2 & 1.853 & 0.926 & & \\
\hline Genotype & 24 & 169.815 & 7.075 & 8.64 & $0.000 * *$ \\
\hline Error & 48 & 39.266 & 0.818 & & \\
\hline Total & 74 & 210.935 & & & \\
\hline
\end{tabular}

Mean: 7.862; SEd: 0.738; CD (.05): 1.484; CD (.01): 1.981; CV\%: 11.50

Table.3 ANOVA for days to wilt

\begin{tabular}{|l|c|c|c|c|c|}
\hline Source & df & SS & MS & F & PROB \\
\hline Replication & 7 & 70.940 & 10.134 & & \\
\hline Genotype & 24 & 4049.920 & 168.746 & 18.943 & $0.000 * *$ \\
\hline Error & 168 & 1496.560 & 8.908 & & \\
\hline Total & 199 & 5617.420 & 28.228 & & \\
\hline
\end{tabular}

Mean: 12.230; SEd: 1.492; CD (.05): 2.946; CD (.01):3.888; CV\%: 24.40 
Table.4 Scale based on Standard Evaluation System for rice (SES)

\begin{tabular}{|l|l|}
\hline Grade & Criteria \\
\hline 0 & No damage \\
\hline 1 & Very slight damage \\
\hline 3 & First and Second leaves of most of the plants partially turns yellowing \\
\hline 5 & Pronounced yellowing and stunting or about half the plants wilted or dead \\
\hline 7 & More than half of the plants dead \\
\hline 9 & All plants dead \\
\hline
\end{tabular}

Fig.1 Damage score and days to wilt across 25 rice landraces screened for BPH resistance

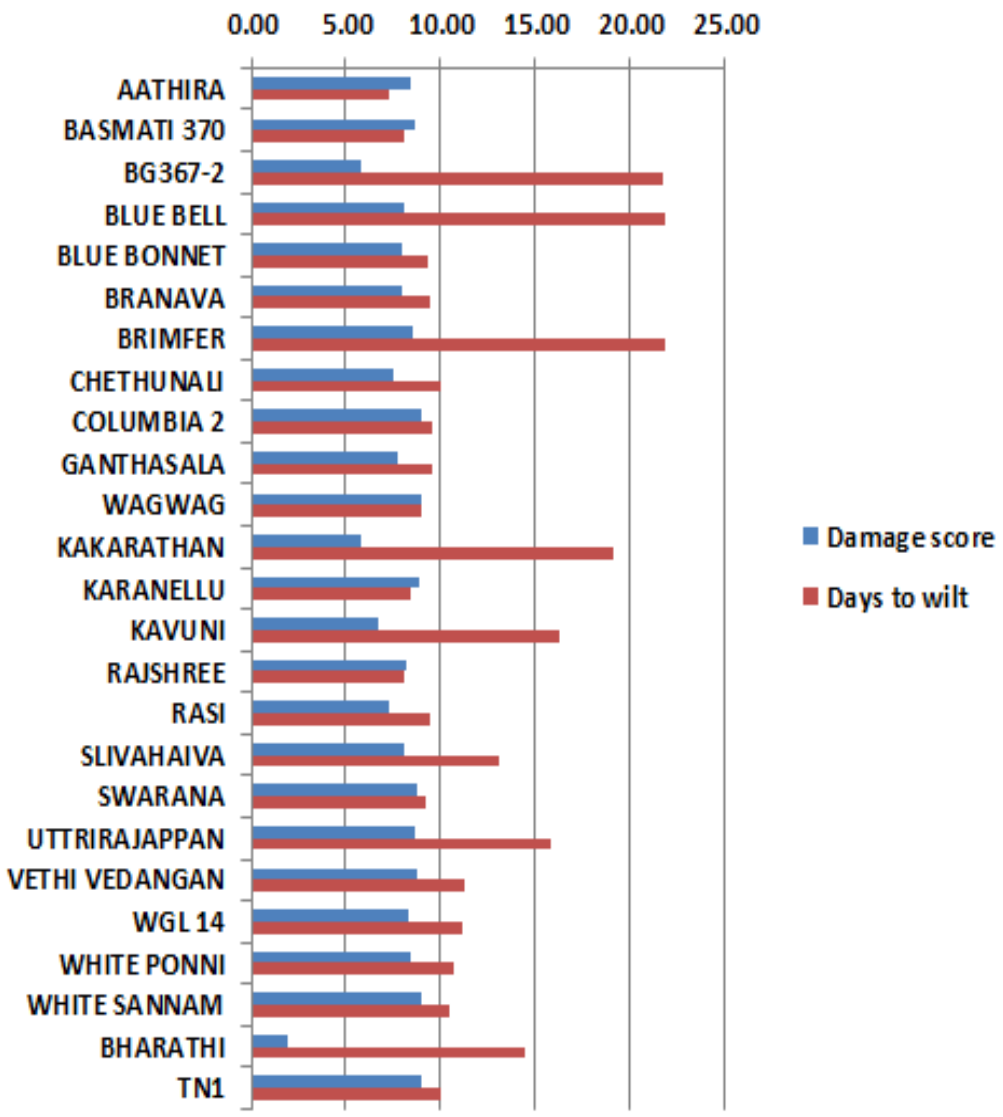

Of the 25 accessions screened Aathira wilted 7.25 days after infestation with BPH whereas Bromfer, Blue bell and BG367-2 took 21 days after infestation indicating high level of tolerance to BPH attack. Bharathi, an accession which was found to be with high level of resistance based MSST score 'over the other accessions wilted 14.50 days after infestation indicating clear difference between the two methods adopted. Other accessions viz.
Karkarathan (19.13 days), Kavuni (16.25 days) and Uttrirajappan (15.88 days) were found to be better than Bharathi based on the days to wilt (Table 1). Though individual plants can be subjected and replicated to assess the level of resistance this method is laborious and time consuming and is not extensively used for screening the rice genotypes for $\mathrm{BPH}$ resistance. 
The comparison made between damage score by MSST and days to wilt across the 25 accessions indicated more variations for days to wilt when compared to damage score (Table 2 and 3). The accessions viz. Bromfer, Blue bell, BG367-2 Karkarathan, Kavuni and Uttrirajappan were found to be better than Bharathi, genotypes known for its high level of resistance by damage score (Figure 1). From this it is very clear that the level resistance will be varying with the parameters employed screening the genotypes and both of the methods are not exposing the causes for resistance or susceptibility.

\section{References}

Bottrell, D. G. and K. G. Schoenly, 2012. Resurrecting the ghost of green revolutions pest: the brown planthopper as a recurring threat to high-yielding rice production in tropical Asia. J Asia-Pacific Entomol., 15:122-40.

Gallagher, K. D., P. E. Kenmore and K. Sogawa, 1994. Judicial use of insecticides deter planthopper outbreaks and extend the life of resistant varieties in Southeast Asian rice. In: Denno RF, Perfect TJ, editors. Planthoppers: their ecology and management. New York: Chapman \& Hall. p. 599-614.

Heinrichs, E.A., F.G. Medrana and H. R. Rapusas, 1985. Genetic evaluation for insect resistance in rice. Los Banos, Philippines, International Rice Research Institute. 356p.

Hossain, M., 1997. Rice supply and demand in Asia: a socioeconomic and biophysical analysis. In: Application of Systems Approaches at the Farm and Regional Levels (Teng, P.S. et al., Eds.). Kluver Academic Publishers, Dordrecht.
IRRI, 1996. Standard Evalution System for Rice. 4th edn., Manila, The Philippines.

MacLean, J.L., 2002.Rice Almanac. International Rice Research Institute, Los Banos; West Africa Rice development Association, Bonake, Ivory Coast; International Centre for Tropical Agriculture, Cali; Food and Agriculture Organisation, Rome

Pontius, J., R. Dilts and A. Bartlett, 2002. From farmer field school to community IPM, ten years of IPM training in Asia. FAO Regional office for Asia and the Pacific. Pp. 106.

Sogawa, K., 1982. The rice brown plant hopper: feeding physiology and host plant interactions. Annu. Rev. Entomol. 27: 4973.

Soundararajan, R.P., P. Kadirvel, K. Gunathilagaraj and M. Maheswaran, 2004. Mapping of quantitative trait loci associated with resistance to brown planthopper in rice by means of a doubled haploid population. Crop Sci., 44: 2214 2220.

Suenaga, H. and K. Nakatsuka, 1958. Studies on forecasting of the occurrence of leafhoppers in the paddy field. The first Special Research Report on the Disease and Insect Forecasting, Promotion Office, Ministry of Agriculture and Forestry, Japan. 468 p.

US Census Bureau, 2009. International database, World population: 1950-2050 shttp://www.census.gov/ipc/www/idb/wor ldpopgraph php

Velusamy, R., E. A. Heinrichs and F.G. Medrano, 1986. Greenhouse techniques to identify field resistance to the brown planthopper, [Nilaparvata lugens (Stål)] (Homoptera: Delphacidae) in rice cultivars. Crop Prot., 5: 328-333.

\section{How to cite this article:}

Timmanagouda, S.P. and Maheswaran, M. 2017. Phenotypic Screening for Brown Planthopper [Nilaparvata lugens (Stål)] Resistance in Rice (Oryza sativa L.). Int.J.Curr.Microbiol.App.Sci. 6(12): 858-863. doi: https://doi.org/10.20546/ijcmas.2017.612.092 